\title{
Solar Facade Module for Nearly Zero Energy Building. Extended Test Period
}

\author{
Toms MOLS ${ }^{1 *}$, Ruta VANAGA ${ }^{2}$, Andra BLUMBERGA $^{3}$ \\ ${ }^{1-3}$ Institute of Energy Systems and Environment, Riga Technical University, Azenes iela 12/1, \\ Riga, LV 1048, Latvia
}

\begin{abstract}
The study presented in this paper is a continued research of preceding tests of small-scale passive solar wall module to explore 1) the behaviour of solar wall module in various setups for an extended 48 -hour period of time, and 2) the performance of solar module with and without fine metal wires as heat exchange enhancers. Eight different solar wall module setups were assembled and tested in a precisely controlled environment. The study reassures observations and conclusions made in previous research and provides new conclusions. Modules that can harvest more solar radiation in the charging phase are exposed to higher heat losses at the discharge phase to the external environment. Module setups that reach stable heat flow fast and respectively melt PCM volume effectively, create a problem of not managing to harvest more of the available solar radiation.
\end{abstract}

Keywords - Fresnel lens, PCM, optimization, adaptive building envelope, building energy efficiency.

\section{INTRODUCTION}

Directive 2010/31/EU urged building energy efficiency declaring that by the end of 2020 all new buildings must comply with nearly zero energy building (NZEB) definition [1]. $40 \%$ of primary energy and respective GHG emissions are generally produced by buildings and construction according to International Energy Agency (IEA) reports [2].

Moreover, highly energy efficient and decarbonized building stock and effective long-term renovation strategies should deliver the necessary progress for conversion of existing buildings into nearly zero-energy buildings. European Union Member States are encouraged to provide specific guidelines and set measurable, targeted actions. Equal acces s to financing must be provided to worst performing segments of the national building stock, social housing, and other consumers with limited options for improvement [3].

Long-term renovation strategies should be established in order to support renovation of national stock of residential and non-residential buildings, thus reaching decarbonized building stock by 2050 [3].

Nearly-zero and plus energy buildings have been researched and developed extensively and renewable energy plays a significant role in reaching these energy performance characteristics. Renewable energy harvesting and use on site is somewhat unreliable and unpredictable, because wind or solar power are not available on demand. Therefore, energy storage problems arise and need to be solved [4]-[6].

* Corresponding author.

E-mail address: toms.mols@rtu.lv 
There are numerous ways to store energy - thermal energy storage, batteries, potential energy of a hydro storage, thermochemical solutions [7]. However, in this paper energy storage via phase-change materials (PCM) is reviewed.

PCM materials are applied in structures passively with no auxiliary energy demand or actively in systems that need auxiliary energy. Passive systems encompass phase change materials that are embedded in a building's enclosing structures like walls, floors, ceilings, windows, tiles and boards [8].

As phase change materials possess low thermal conductivity, the application can be optimized via heat transfer enhancers like metal mesh or fiber submerged into PCM or solar concentrators if solar energy is harvested [9]-[11].

Paper presents research where PCM volume is incorporated in a wall structure with no auxiliary energy provided. PCM module passively absorbs energy from an external source and releases to indoor volume.

The decision for a continuation of tests to an extended period of time had been made in order to observe or approach full PCM charge-discharge cycle. Secondly, in addition to extended testing period, two new setups of solar wall module are created using metal mesh heat transfer enhancers in order to lower costs, weight and constructional complexity of the module.

The objective of this study is to continue exploration of heat transfer processes in a smallscale passive solar wall module that contains phase change material, copper heat transfer enhancers and a Fresnel lens as the solar concentrator. An integral part of the study are tests for observing the temperatures and heat flow processes of PCM module over two days that has not been assessed before.

\section{TeSTING SETUP}

\subsection{Previous Experimental Studies and Adjustments}

This study of PCM module is succession of a series of passive solar wall research [12][14]. After review of previously received results it was decided to:

- Add additional test setups of the module using heat exchange enhancers - fine copper wires submerged in PCM,

- Test the module in specific outdoor temperature conditions for a longer - two-day period.

Eight small scale passive solar wall modules were constructed and tested in a laboratory in a precisely controlled environment. Each module encompasses two main elements - PCM container $(127 \times 127 \times 60 \mathrm{~mm})$ supplemented with heat transfer enhancers and heat transfer unit $(127 \times 127 \times 71 \mathrm{~mm})$ (Fig. 1). Table 1 lists the constructive differences among all 8 tested setups.

By analogy with the historic studies for heat exchange optimization, three alternatives for the heat transfer unit are reviewed - still air, aerogel filling and insulated cone [14]. All three alternatives are tested in two regimes - with solar concentrator - Fresnel lens and with acrylic glass that does not focus solar radiation in any specific point of PCM container area. Two kinds of wall modules are made -3 modules (cone, aerogel, air space) Fresnel lens solar concentrator installed, in other 3 modules (cone, aerogel, air space) clear-cut, translucent PMMA acrylic glass is installed. Fresnel lens dimensions cover the solar module outer dimensions [14], 15]. 


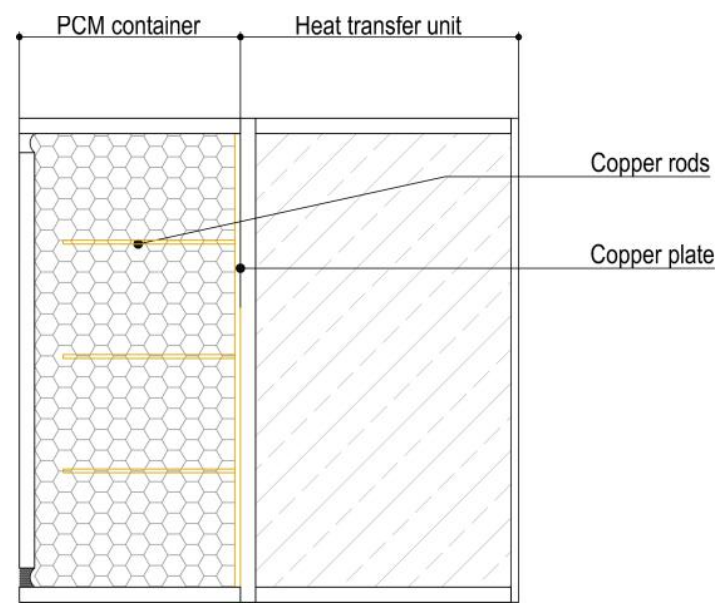

Fig. 1. Passive solar module: schematic view.

TABLE 1. Constructive DifFerenCes IN TeSt Setups

\begin{tabular}{ll}
\hline Setup & Constructive components \\
\hline Setup 1 & Fresnel lens, cone and aerogel. \\
Setup 2 & PMMA glass and aerogel. \\
Setup 3 & Fresnel lens and aerogel. \\
Setup 3.1. & Fresnel lens, aerogel, without fine metal enhancer. \\
Setup 4. & Fresnel lens and air. \\
Setup 4.1 & Fresnel lens, air and fine metal enhancer. \\
Setup 5 & PMMA glass and air. \\
Setup 6 & PMMA glass, cone and aerogel. \\
\hline
\end{tabular}

Additionally, two solar modules are made: PCM container with heat transfer enhancer fine copper wires (Fig. 2), combined with Fresnel lens and aerogel and PCM container without heat transfer enhancers combined with PMMA acrylic glass and no insulation material. The phase change material Paraffin RT21HC (Rubitherm) with characteristics listed in Table 2 is used for this experiment.

For the solar module to maintain the conditions and environment of previous experiments, all eight modules during testing were inserted in an identical insulated test box $(557 \times 557 \times 600 \mathrm{~mm}$ ) (Fig. 3). $15 \mathrm{~mm}$ plywood forms outer walls. $200-300 \mathrm{~mm}$ mineral wool leaving 'indoor space' with dimensions $140 \times 140 \times 127 \mathrm{~mm}$. The set of box and module is placed in a refrigeration chamber with the possibility to precisely control temperature thus simulating outdoor environment. 


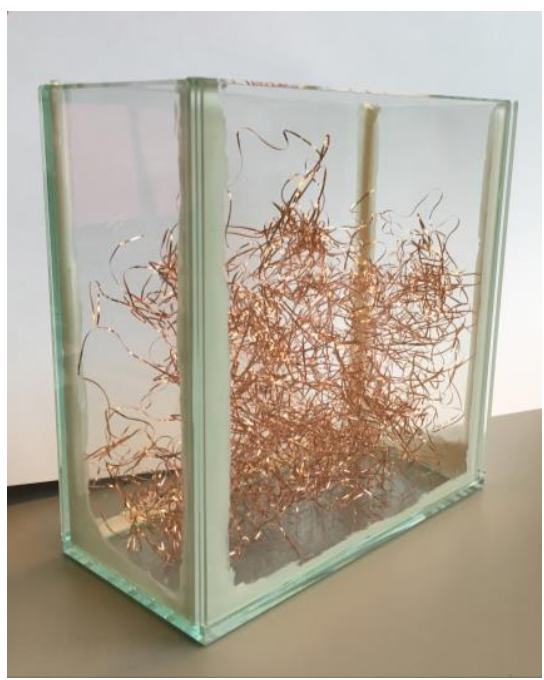

Fig. 2. PCM container with fine copper wires as heat transfer enhancer element.

\section{TABLE 2. MAIN CHARACTERISTICS OF PARAFFIN RT21HC [16]}

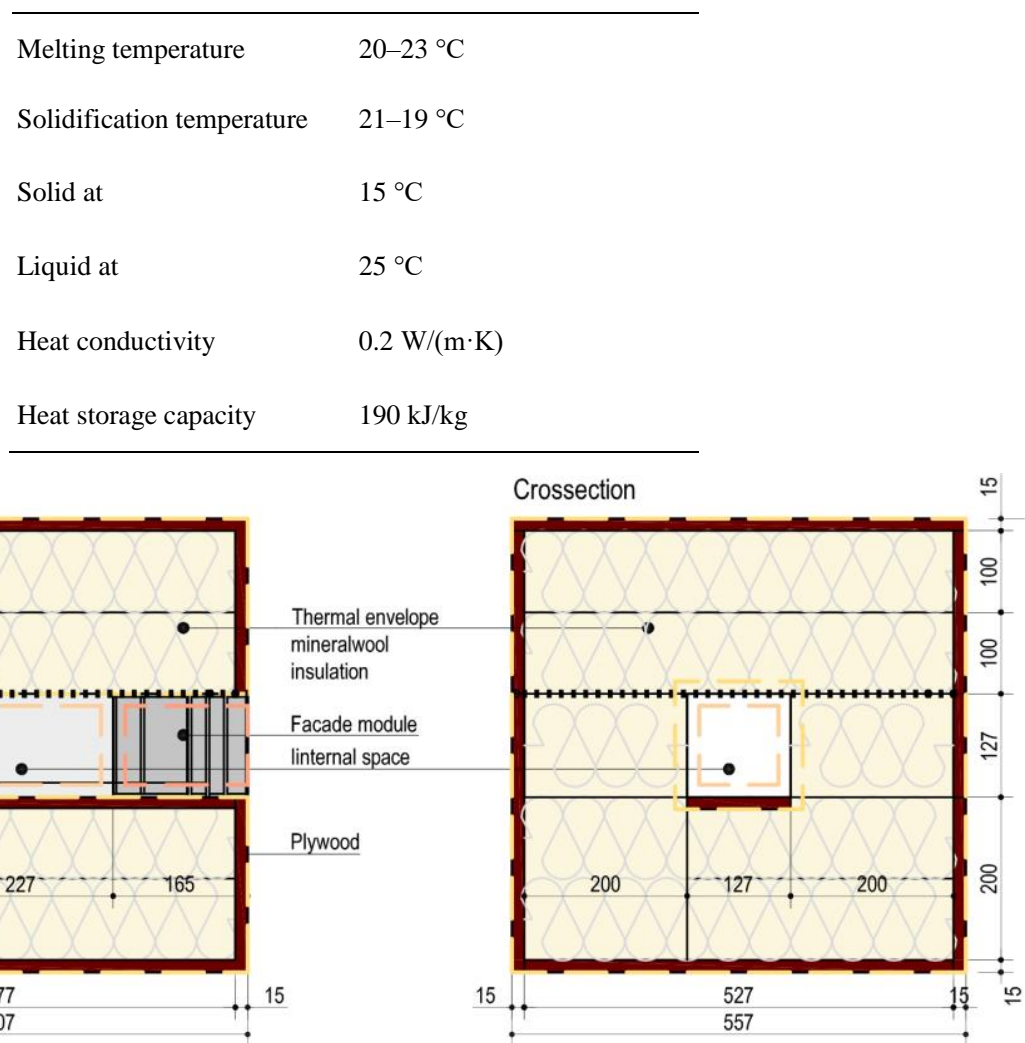

Fig. 3. Test box section (units in $\mathrm{mm}$ ). 
A special halogen lamp GE SUPER CP60 EXC VNS 230V | 1000W G16d 3200K | General Electric combined with dimmer UNI BAR Elation professional was used to simulate solar radiation that acts on wall module. The wall modules were exposed to solar radiation of $1000 \mathrm{~W} / \mathrm{m}^{2}$ during heating phase.

Respecting the setup of previous tests, the distance between the solar radiation simulation lamp and test box was kept repeatedly at $2329 \mathrm{~mm}$ (Fig. 4). The experiment lasted 48 hours with solar radiation available for 7 hours 39 minutes (outdoor temperature $+15^{\circ} \mathrm{C}$ ) from the beginning of the testing period. For the rest of the period, 40 hours 21 minute, the temperature in the refrigeration chamber is maintained at $+10^{\circ} \mathrm{C}$.
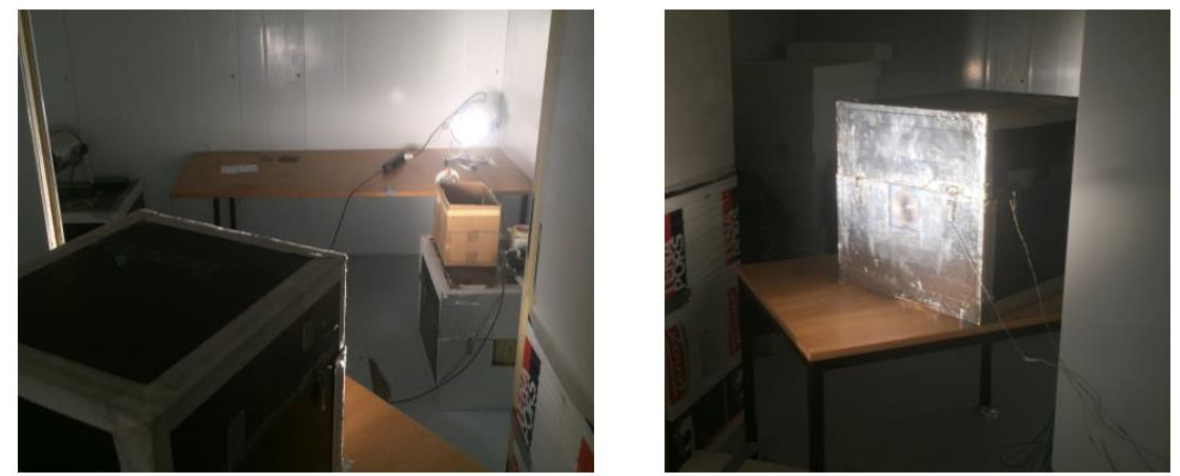

Fig. 4. Experimental setup.

\subsection{Monitoring Equipment}

Parameters during the experiment are registered via Multipurpose data logger CR1000| Campbell Scientific combined with multiplexer AM16/32 | Campbell Scientific. Data is logged once every minute. Solar radiation is measured by pyranometer CMP3 | Kipp \& Zonen. Type $\mathrm{K}$ thermocouples are used to measure temperature.

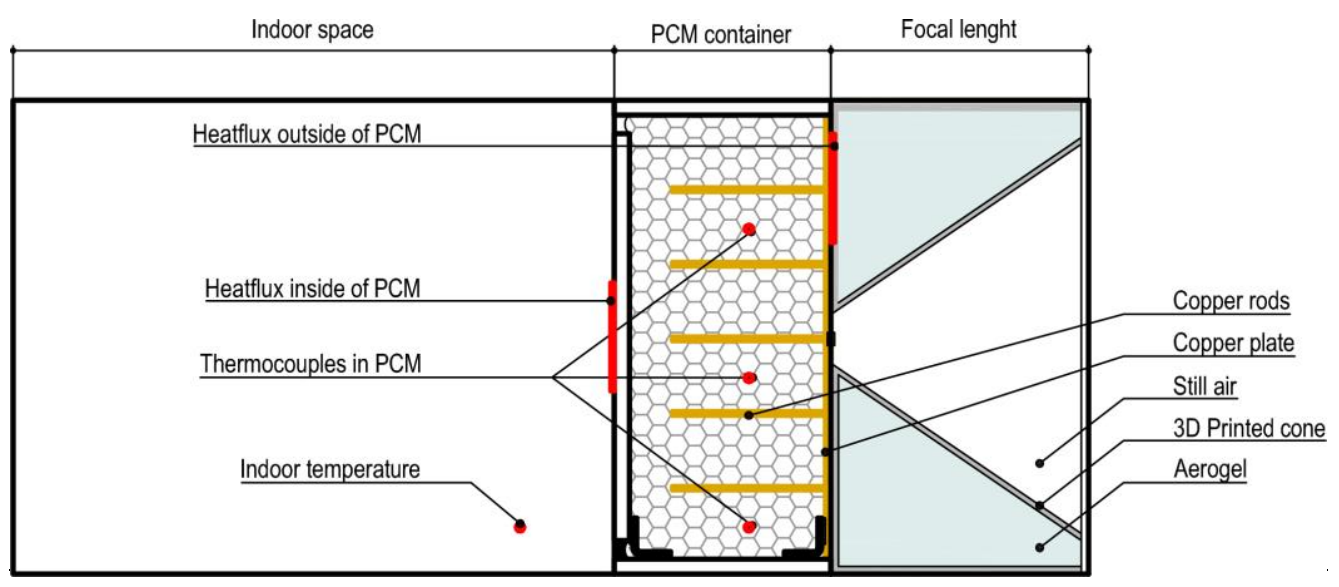

Fig. 5. Monitoring equipment scheme. 
By analogy with preceding experimental study there were 5 thermocouples used to collect the temperature data during the experiments (Fig. 5). Three thermocouples were in the PCM container close to the back wall to monitor heating and heat distribution process in different layers - lower, middle and upper layer. The fourth thermocouple measured indoor space temperature. The fifth thermocouple was placed outside the box at the wall of refrigeration camera to log the "ambient" temperature.

Two Sequoia SHF meters were placed on the outside and inside walls of the PCM container to collect heat flow data. Heat flow meters provide information on the heat transfer process dynamics in the solar wall module.

\section{RESUlts}

\subsection{Order of the Experiment}

One testing cycle of $48 \mathrm{~h}$ is monitored during which the PCM is charging and discharging. The duration of the charging phase is $7 \mathrm{~h} 39$ minutes, constant solar simulation $1000 \mathrm{~W} / \mathrm{m}^{2}$ and ambient temperature of $15^{\circ} \mathrm{C}$. The duration of discharging phase was $41 \mathrm{~h} 21$ minutes at an ambient temperature of $10^{\circ} \mathrm{C}$.

\subsection{Heating and Cooling Temperatures of PCM}

Like in the previously performed research [14] the heating of PCM occurs gradually from the upper to lower layers of PCM volume. To analyse solar wall module performance, average values of temperature are calculated from the collected measurements (Fig. 6).

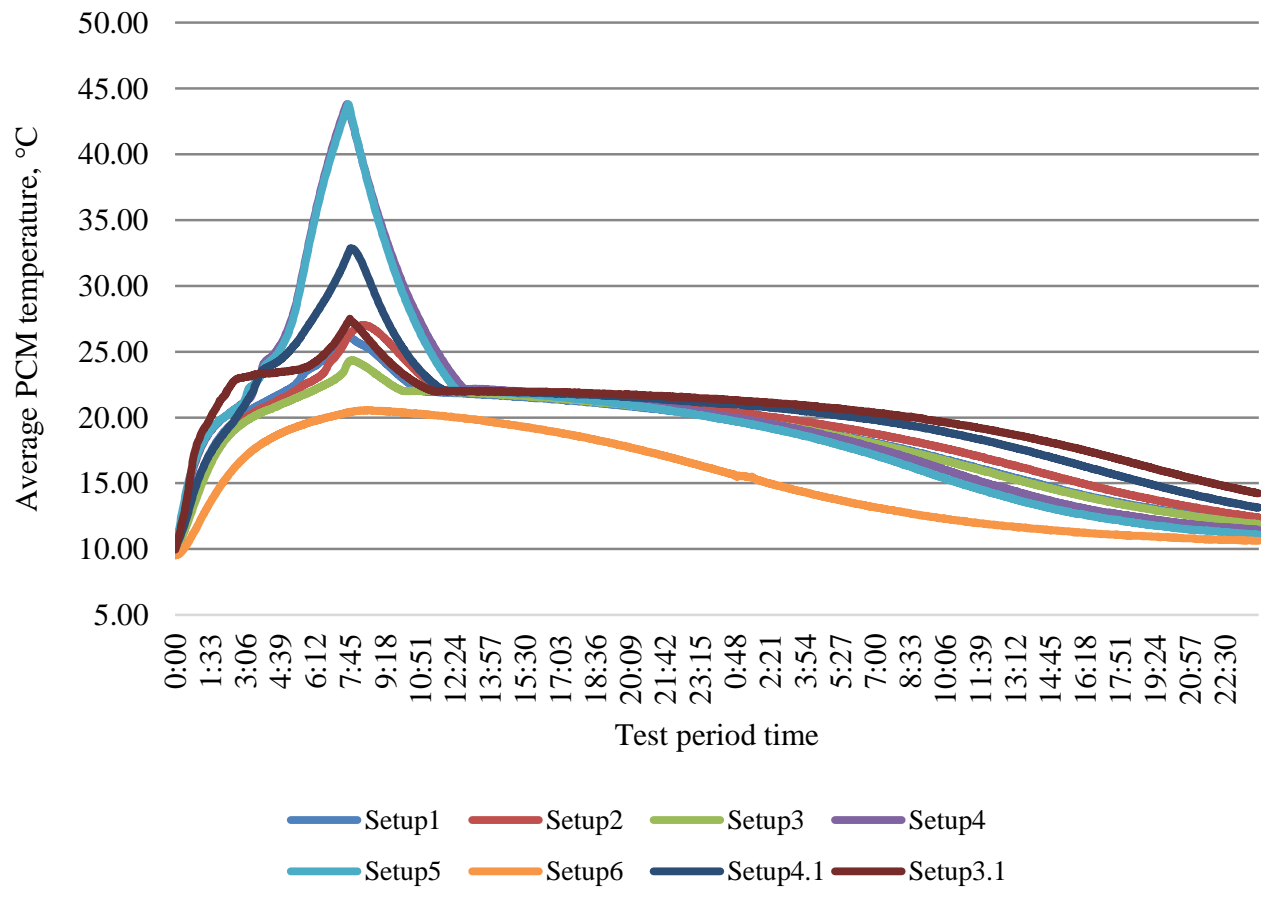

Fig. 6. Average PCM temperature in various setups. 
Average PCM temperature is beginning to rise rapidly at 3 hours 33 minutes in modules with Setup 3.1, Setup 4, Setup 4.1. and Setup 5. Whereas Setup 1, Setup 2, Setup 3 and Setup 3.1. show accelerated temperature increase only at 5 hours and 30 minutes when average PCM temperature has reached $23.6{ }^{\circ} \mathrm{C}$ and above. Lastly, Setup 6 does not even reach the PCM melting temperature. Periods with steep increase of temperature indicate PCM accumulating energy in sensible heat phase.

The solar radiation simulator is turned off after 7 hours 39 minutes of functioning. All of the modules excluding Setup 6 show continuation of temperature increase after the solar radiation simulation has stopped. This momentum is explained by PCM layers or fractions that have not melted completely. Whereas, if whole PCM volume has melted, the cooling commences at the moment the solar radiation is interrupted.

As the testing and monitoring period of this experiment was longer than in the previous research -48 hours instead of 24 hours, it can be observed that after one day the average PCM temperature, excluding Setup 6, is in the range from 19.95 to $21.42{ }^{\circ} \mathrm{C}$. At this moment the leader is Setup 3.1. with other setups following closely. Continuing monitoring the difference between leader and other increases: at the end of a two-day period the leading Setup 3.1 is at $14.23{ }^{\circ} \mathrm{C}$ and Setup 4.1 follows with $13.15^{\circ} \mathrm{C}$ making $1.08{ }^{\circ} \mathrm{C}$ difference.

Measurements taken allow for maximum and minimum temperatures to be observed of each setup (Table 3). Besides the highest maximum temperature reached with Setup 4 and Setup 5 modules (reaching almost identical parameters), the construction and lack of insulation does not secure highest minimum temperature at the end of testing period. This reassures that if no means of insulation are foreseen, heat transfers outside to external environment.

TABLE 3. HighEST AND LOWEST AVERAGE PCM TEMPERATURE

\begin{tabular}{llc}
\hline Type of Setup & Max t, ${ }^{\circ} \mathbf{C}$ & Min t, ${ }^{\circ} \mathbf{C}$ \\
\hline Setup 1 (Fresnel lens, cone and aerogel) & 26.32 & 11.85 \\
Setup 2 (PMMA glass and aerogel) & 27.02 & 12.40 \\
Setup 3 (Fresnel lens and aerogel) & 24.36 & 11.90 \\
Setup 3.1. (Fresnel lens, aerogel, without fine metal enhancer) & 27.49 & 14.23 \\
Setup 4. (Fresnel lens and air) & 43.82 & 11.46 \\
Setup 4.1. (Fresnel lens, air and fine metal enhancer) & 32.86 & 13.14 \\
Setup 5 (PMMA glass and air) & 43.83 & 11.11 \\
Setup 6 (PMMA glass, cone and aerogel) & 20.56 & 10.62 \\
\hline
\end{tabular}

\subsection{Room Temperature}

Monitored indoor space temperatures are displayed in Fig. 7. By analogy with preceding studies, indoor temperature continues to rise and reaches its peak values after the solar radiation simulation is stopped. This observation indicates that thermal energy from PCM volume continues to provide heat for indoor space while the external conditions have 
changed. Highest temperature can be reached via Setup 4 - the same as with average PCM temperature.
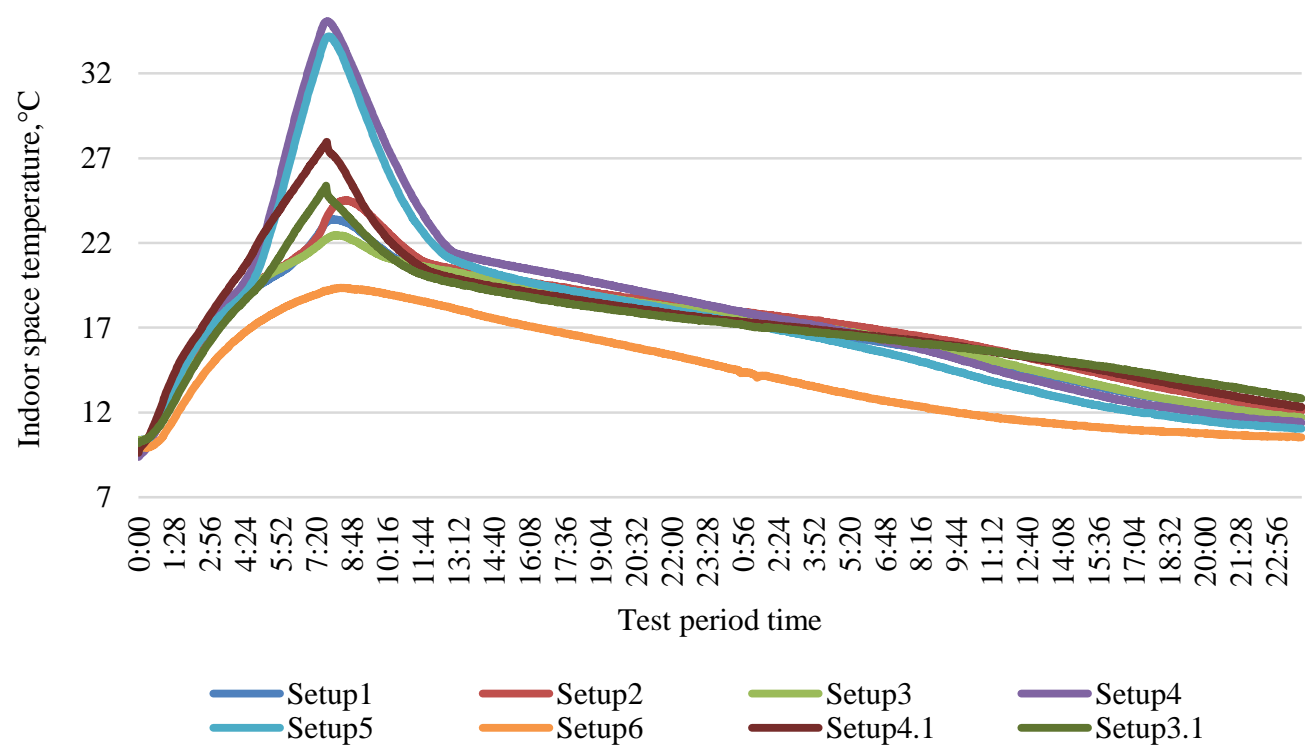

Fig. 7. Indoor space temperature in various setups.

Reviewing monitoring results after the first 24 hours, the leader of indoor temperature is Setup 4 at $18.17{ }^{\circ} \mathrm{C}$ with other Setups leading closely. However, after completing the twoday period, the leaders change - Setup 3.1 is at $12.83{ }^{\circ} \mathrm{C}$ and other Setups follow, leaving Setup 6 only at $10.53{ }^{\circ} \mathrm{C}$ that is $0.53{ }^{\circ} \mathrm{C}$ above external temperature of testing environment.

\subsection{Heat Flow Observations}

Reviewing Setup 2 (PMMA glass and aerogel) and Setup 4 (Fresnel lens and air) heat flow measurement data following observations can be made. In Setup 2 (Fig. 8) at first the heat flow from outer part of PCM volume is accelerating swiftly and after 1 hour and 47 minutes reaches a relatively constant value that is kept until the solar radiation simulation is turned off at 6 hours 39 minutes. Then the module goes into discharge period and emits heat to outer and internal environments. After 24 hours a significant heat flow is still observed. This lasts for the whole testing period of two days but with lesser intensity.

Reviewing heat flow measurements of Setup 4 module in Fig. 9, at first it shows the same behaviour as Setup 4 - rapid heat flow rise at approximately 1 hour and 57 minutes reaching stable range of flow, however at 5 hours and 2 minutes a linear decrease in heat flow from the outside is detected. 


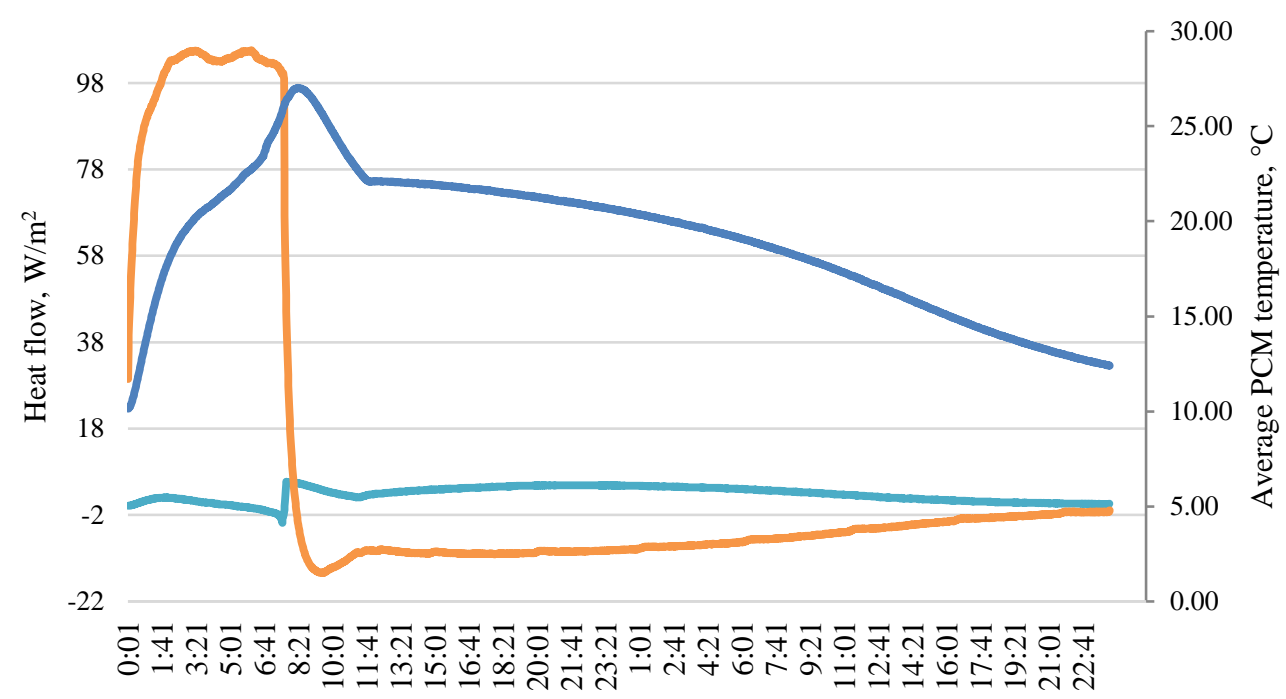

Test period time

$\longrightarrow$ mV Smp HF inside $\quad$ mV Smp HF outside $\quad$ Tavg

Fig. 8. Heat flow and PCM average temperature, Setup 2.

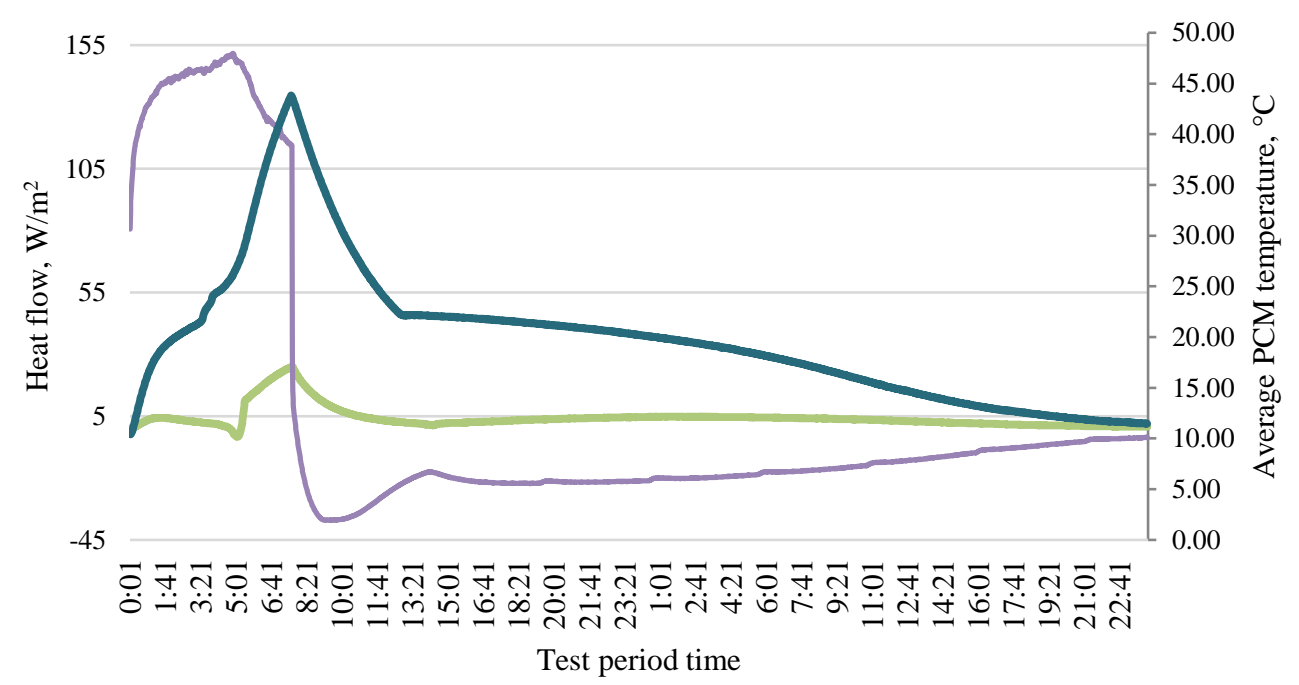

mV Smp HF inside $\quad$ mV Smp HF outside $\quad$ Tavg

Fig. 9. Heat flow and PCM average temperature, Setup 4.

This heat flow observation is explained by the fact that Setup 4 with Fresnel lens was able to melt the PCM volume at a faster pace. When the PCM section is fully melted, the receiving 
capacity of heat declines. Therefore, after the 5 hour and 2-minute mark until the solar radiation simulator is switched off, the solar radiation generated was not effectively harvested by the solar facade module.

\section{CONCLUSIONS AND DiscuSSION}

The continuation of the study and continued tests of passive solar wall module for an extended period of time presents results of the impact of phase change material embedded in the thermal envelope on indoor temperature in the heating season. Experimental study of passive solar wall modules containing PCM provides several findings:

- 48-hour testing cycle discovered that after a longer period of observation, the leaders and rankings change compared to the results from a 24 -hour testing cycle.

- The study shows solar module behaviour in the first 24 hours similar to results previously tested thus confirming the observations of previous studies.

- Module Setups that allow for reaching stable heat flow fast and respectively melt PCM volume more effectively, create a problem of not managing to harvest more of the available solar radiation. Optimization with PCM material and volume should be carried out in order to find a solution. Ideal Setup of solar module would rapidly harvest solar energy and then enter self-insulated condition that allows for maximum of thermal energy to be emitted indoors.

- Significant differences of peak indoor temperatures were detected. Modules that can harvest more solar radiation in the charging phase are exposed to higher heat los ses at the discharge phase to the external environment.

- Highest indoor temperature was reached with Setup 4 and Setup 5. However, this heat was lost ineffectively dissipating to external environment. Highest indoor temperature after a 48-hour period was detected with Setup 3.1 via Fresnel lens, aerogel and without fine metal enhancer. These observations suggest that the application of metal enhancers should be carried out and continuous tests with and without enhancers should be concluded.

- Indoor space volume within this research and testing is relatively small and greater volumes might affect the performance of PCM modules. The interaction between changing energy demands and heat emitted from the PCM module should be explored in further research.

Described tests and results indicate performance capabilities and points of improvement for solar module designs and may be of assistance in further research and development of adaptive building envelope.

It is suggested for further research to consider: 1) possibilities to optimize passive solar wall module construction taking advantage of the fact that upper layers of PCM volume are warming up faster than lower layers, 2) continuing optimization of metal fraction in PCM, 3) scaling the testing on a larger scale with solar wall module application in outdoor environment with real weather conditions

\section{ACKNOWLEDGEMENT}

The research is funded by the Ministry of Economics of the Republic of Latvia, project "Improvement of building energy efficiency technologies (I-BEET)" project No. VPP-EM-EE-2018/1-0003. 


\section{REFERENCES}

[1] Directive 2010/31/EU of the European Parliament and of the Council of 19 May 2010 on the energy performance of buildings. Official Journal of the European Union 2010:L153/13.

[2] IEA. Policy Pathways Brief: Modernising Building Energy Codes 2017. International Energy Agency, 2017.

[3] Directive (EU) 2018/844 of the European Parliament and of the Council of 30 May 2018 amending Directive 2010/31/EU on the energy performance of buildings and Directive 2012/27/EU on energy efficiency, PE/4/2018/REV/1. Available: http://data.europa.eu/eli/dir/2018/844/oj

[4] Passer A., et al. The impact of future scenarios on building refurbishment strategies towards plus energy buildings. Energy and Buildings 2016:124:153-163. https://doi.org/10.1016/j.enbuild.2016.04.008

[5] Attia S., et al. Overview and future challenges of nearly zero energy buildings (nZEB) design in Southern Europe. Energy and Buildings 2017:155:439-458. https://doi.org/10.1016/j.enbuild.2017.09.043

[6] Bot K., et al. Energy performance of buildings with on-site energy generation and storage - An integrated assessment using dynamic simulation. Journal of Building Engineering 2019:24:100769. https://doi.org/10.1016/j.jobe.2019.100769

[7] Krese G., Koželj R., Butala V., Stritih U. Thermochemical seasonal solar energy storage for heating and cooling of buildings. Energy and Buildings 2018:164:239-253. https://doi.org/10.1016/j.enbuild.2017.12.057

[8] Kasaeian A., et al. Experimental studies on the applications of PCMs and nano-PCMs in buildings: A critical review. Energy and Buildings 2017:154:96-112. https://doi.org/10.1016/j.enbuild.2017.08.037

[9] Al-Maghalseh M., Mahkamov K. Methods of heat transfer intensification in PCM thermal storage systems: Review paper. Renewable and Sustainable Energy Reviews 2018:92:62-94. https://doi.org/10.1016/j.rser.2018.04.064

[10] Choi D. H., Lee J., Hong H., Kang Y. T. Thermal conductivity and heat transfer performance enhancement of phase change materials (PCM) containing carbon additives for heat storage application. International Journal of Refrigeration 2014:42:112-120. https://doi.org/10.1016/j.ijrefrig.2014.02.004

[11] Fan L., Khodadadi J. M. Thermal conductivity enhancement of phase change materials for thermal energy storage: A review. Renewable and Sustainable Energy Reviews 2011:15(1):24-46. https://doi.org/10.1016/j.rser.2010.08.007

[12] Vanaga R., et al. Solar facade module for nearly zero energy building. Energy 2018:157:1025-1034. https://doi.org/10.1016/j.energy.2018.04.167

[13] Mols T., et al. Experimental study of small-scale passive solar wall module with phase change material and Fresnel lens. Energy Procedia 2018:147:467-473. https://doi.org/10.1016/j.egypro.2018.07.048

[14] Sirmelis R., Vanaga R., Freimanis R., Blumberga A., Solar Facade Module for Nearly Zero Energy Building. Optimization Strategies. Environmental and Climate Technologies 201:23(3):170-181. https://doi.org/10.2478/rtuect2019-0087

[15] Edmund Optics [Online]. [Accessed 20.03.2020]. Available: https://www.edmundoptics.eu/p/5quot-X-5quot-4quotfocal-length-fresnel-lens/6959

[16] Rubitherm Technologies GmbH [Online]. [Accessed 20.03.2020]. Available: https://www.rubitherm.eu/media/products/datasheets/Techdata_-RT21HC_EN_06082018.PDF

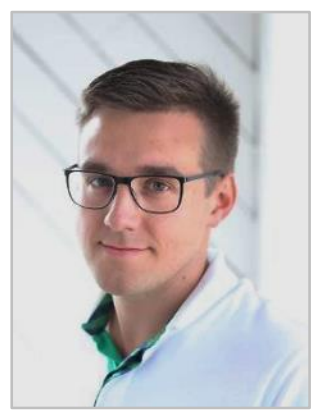

Toms Mols has received a master's degree in Environmental Science in Riga Technical University (RTU) in 2015 focusing his study on indoor air quality. Toms is a project manager in an engineering company dealing with infrastructure projects from design to implementation phase. Author of 5 publications and currently on his fourth year of doctoral studies in Environmental Engineering at RTU. Research is focused on energy efficiency in buildings, modelling of climate adaptive enclosures and energy storage for nearly zero energy buildings.

E-mail: toms.mols@gmail.com 

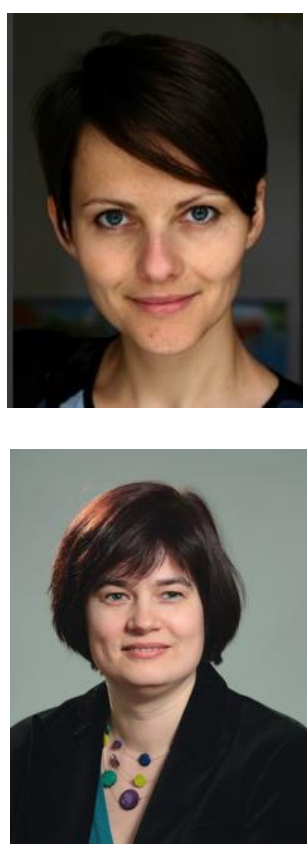

Ruta Vanaga, Dr. sc. ing., works as a leading researcher at Institute of Energy Systems and Environment, Riga Technical University, Latvia. Since 2004 she has qualification of architect, in 2006 she earned engineering master degree of architecture from Faculty of Architecture, RTU. In 2019 she earned doctoral degree of environmental science. She has worked as an architect and energy auditor from 2010 till 2018. Research interests are related to biomimicry, passive houses, innovative building systems, energy efficiency of buildings. Email: Ruta.Vanaga@rtu.lv

Andra Blumberga, Dr. sc. ing., professor, works for Institute of Energy Systems and Environments, Riga Technical University since 2001. She has been working with energy efficiency since 1992. Her main research interest is energy efficiency both from technical and policy sides. She has managed many national and international research and other projects since 1999, e.g. "Assesment on energy efficiency and use of renewable energy sources in Latvia by $2020 "$, "Climate Technology development modeling in energy sector", "Energy strategy 2030 for Latvia", "System Dynamics modeling for energy sector in Latvia". She has been working as the World Bank energy expert for development of the Green Investment Scheme in Latvia. She is an author of more than 80 publications and 14 monographs.

E-mail: andra.blumberga@rtu.lv

ORCID iD: http://orcid.org/0000-0002-4712-4794 